\title{
Clinical Characteristics of Amiodarone-Induced Thyrotoxicosis and Hypothyroidism in Japan
}

\author{
Kanji SATO, Megumi MiYAKAWA, Miyuki ETO, TaKaKo INABA*, Naoki MATSUDA*, \\ TsuYoshi SHIGA*, SATOSHI OHNISHI*, HIROSHI KASANUKI*
}

\author{
Department of Medicine, Institute of Clinical Endocrinology, Tokyo Women's Medical University, Shinjuku-ku, Tokyo \\ 162-8666, Japan \\ * Department of Cardiology, The Heart Institute of Japan, Tokyo Women's Medical University, Tokyo Japan
}

\begin{abstract}
Since amiodarone was introduced in Japan in 1992, the incidence of the drug-induced thyroid dysfunction has been increasing. We studied the thyroid function of 13 patients with amiodarone-induced thyrotoxicosis (AIT) and 11 patients with amiodarone-associated hypothyroidism (AAH) who had been referred to our Institute in the last 6 years. AIT and AAH developed after $39 \pm 21$ and $20 \pm 16$ months of amiodarone treatment, respectively. One patient developed AAH followed by AIT. The AIT ranged from subclinical to overt thyrotoxicosis. Four patients with moderate to marked AIT were treated with methimazole. Their thyrotoxicosis persisted for 3 to 9 months, despite administration of antithyroid agents. One patient with mild thyrotoxicosis was treated with prednisolone, resulting in a euthyroid state in a few months. Eight patients with asymptomatic to moderate thyrotoxicosis resolved spontaneously without any treatment. In four asymptomatic patients with AIT, serum levels of $\mathrm{T}_{3}$ and $\mathrm{T}_{4}$ were in the upper normal range or slightly high $(<12 \mu \mathrm{g} / \mathrm{dl})$, accompanied by suppressed $\mathrm{TSH}(<0.1$ $\mu \mathrm{U} / \mathrm{ml}$ ) and high thyroglobulin levels, suggesting destruction-induced thyrotoxicosis. Such a subclinical thyrotoxicosis developed repeatedly in one patient. Ultrasonographic studies revealed no nodular lesion in the thyroid, and color flow Doppler sonography demonstrated no hypervascularity in the thyroid gland in any AIT patient. Although it is postulated in Europe that there are two types of AIT, namely type I, which develops in patients with latent Graves' disease or toxic multinodular goiter, and type II, which develops in an apparently normal thyroid as destructive thyroiditis, all AIT patients we have seen so far had developed destructive type AIT. Sufficient intake of iodide and a very low incidence of toxic multinodular goiter may account for the rare incidence of type I AIT in our country. Mild to moderate AIT resolved spontaneously without discontinuing amiodarone, but it was discontinued in two of 13 AIT patients because of extrathyroidal adverse reactions.
\end{abstract}

Key words: Amiodarone, Thyrotoxicosis, Hypothyroidism, Color flow Doppler sonography, Iodide

(Endocrine Journal 46: 443-451, 1999)

\begin{abstract}
AMIODARONE, an effective type III anti-arrhythmic drug, contains a high amount of iodine (37\%). Since approximately $10 \%$ of organic iodine is deiodinated to yield free iodine, it elicits adverse effects
\end{abstract}

Received: November 18, 1998

Accepted: March 25, 1999

Correspondence to: Dr. Kanji SATO, Department of Medicine Institute of Clinical Endocrinology, Tokyo Women's Medical University, Kawada-cho 8-1, Shinjuku-ku, Tokyo 162-8666, Japan on thyroid function [1, 2]. Furthermore, amiodarone has directly cytotoxic effects on human and rodent thyrocytes in vitro [3, 4]. It is therefore well known that the agent elicits various adverse effects on thyroid function, leading to either hypothyroidism or hyperthyroidism [5-7].

In general, amiodarone-associated hypothyroidism (AAH) elicits no significant problem clinically: simple supplementation with L-thyroxine without discontinuing amiodarone is suffice to keep the AAH patients euthyroid. In contrast, amiodarone-in- 
duced thyrotoxicosis (AIT) is difficult to treat, because a lot of iodine accumulated in the thyroid gland, and withdrawal of the agent is not efficient because of its extremely protracted half life of 14-53 days [2]. Furthermore, it is not recommended for patients with life-threatening arrhythmia to discontinue the life-sustaining antiarrythmic. Although mild to moderate AIT may spontaneously resolve, it may be fatal in some protracted cases $[8,9,10]$, indicating that early diagnosis and proper management is mandatory for AIT patients.

AIT is considered to be less frequent in patients living in iodine-sufficient areas [11], but an increasing number of patients with AIT have been reported in Japan $[12,13]$, where iodine intake is still sufficient [14]. In our country, amiodarone was first marketed in October 1992, and more than 200 patients, who had been unresponsive to conventional antiarrythmic agents, were prescribed amiodarone at the Heart Institute of Japan in Tokyo Women's Medical University. For the last 6 years, 13 patients with AIT and 11 with AAH have been referred to the Institute of Clinical Endocrinology for evaluation of thyroid dysfunction. We found that thyrotoxicosis of AIT patients ranged widely from subclinical to overt and that the pathogenesis of AIT is very different from that reported in Europe, where iodine intake is moderately deficient.

\section{Subjects and Methods}

Between 1992 and October 1998, 23 patients with amiodarone-induced thyroid dysfunction were referred to the Institute of Clinical Endocrinology. Thirteen patients developed AIT and eleven AAH. One patient first developed AAH, followed by AIT. When serum levels of $T_{4}$, free $T_{4}, T_{3}$ or free $T_{3}$ were above the normal range, and /or TSH became undetectable $(<0.1 \mu \mathrm{U} / \mathrm{ml})$, at least twice consecutively, at an interval of more than two months, the patients were considered to have developed AIT. When the serum levels of thyroid hormones were decreased or in the lower normal range, and serum levels of TSH were increased to more than $10 \mu \mathrm{U} / \mathrm{ml}$ after several months of amiodarone therapy [1], or increased steadily with progressively decreasing serum levels of $T_{3}$ and $T_{4}$, the patients were considered to have developed AAH. At the first visit, informed consent was obtained and $20 \mathrm{ml}$ of blood was taken for measurement of thyroid hormones, thyroglobulin and TSH receptor antibody (TRAb). Urine was collected for measurement of iodide. Serum levels of $\mathrm{T}_{3}$ (normal range; $90-170 \mathrm{ng} / \mathrm{dl}$ ) and $\mathrm{T}_{4}$ (normal range; $5.1-11.4 \mu \mathrm{g} / \mathrm{dl}$ ) were determined with commercial radioimmunoassay kits. Serum levels of free $\mathrm{T}_{3}$ (normal range; $2.5-5.0 \mathrm{pg} / \mathrm{ml}$ ) and free $\mathrm{T}_{4}$ (normal range; $0.95-1.85 \mathrm{ng} / \mathrm{dl}$ ) were determined using chemiluminescence assay kits. The serum level of TSH (normal range; $0.2-4.0 \mu \mathrm{U} / \mathrm{ml}$ ) was determined with immunoradiometric assay kits. Antithyroid microsomal antibody and antithyroglobulin antibody were determined with commercially available kits (Fuji Rebio, Tokyo, Japan). A reciprocal titer of $1: 100$ or more was considered positive. TRAb was determined by a radioreceptor assay with a commercial kit (Baxter Co., Tokyo). The results were expressed as percentage inhibition of the binding of ${ }^{125} \mathrm{I}$-bTSH. The normal range was between $-10 \%$ to $10 \%$.

The inorganic iodide concentration in urine was determined with a spectrophotometer (Teijin Biochemical Laboratory, Tokyo, Japan) [14], and the data were expressed as $\mathrm{mg}$ iodine/g creatinine.

Color flow Doppler sonography was performed with a $7.5 \mathrm{MHz}$ transducer (Model LOGIQ500, GE Yokogawa Medical System Co., Tokyo, Japan). Qualitative color flow Doppler sonographic signals were classified as follows [16, 17]: pattern 0: absent intraparenchymal vascularity or minimal spots, pattern I: presence of parenchymal blood flow with patchy uneven distribution or intranodular spots; pattern II: mild increase in color flow Doppler signal with patchy distribution, or prominent color flow at the periphery of the nodule; pattern III: markedly increased color flow Doppler signals with diffuse homogenous distribution or marked color flow throughout the entire nodule, including the so called "thyroid inferno" (Fig. 1).

\section{Results}

\section{Thyroid function of patients with AIT and $A A H$}

Thyroid function of patients with AIT and AAH is shown in Tables 1 and 2, respectively. Consistent with previous reports, the serum levels of $T_{3}$, free 

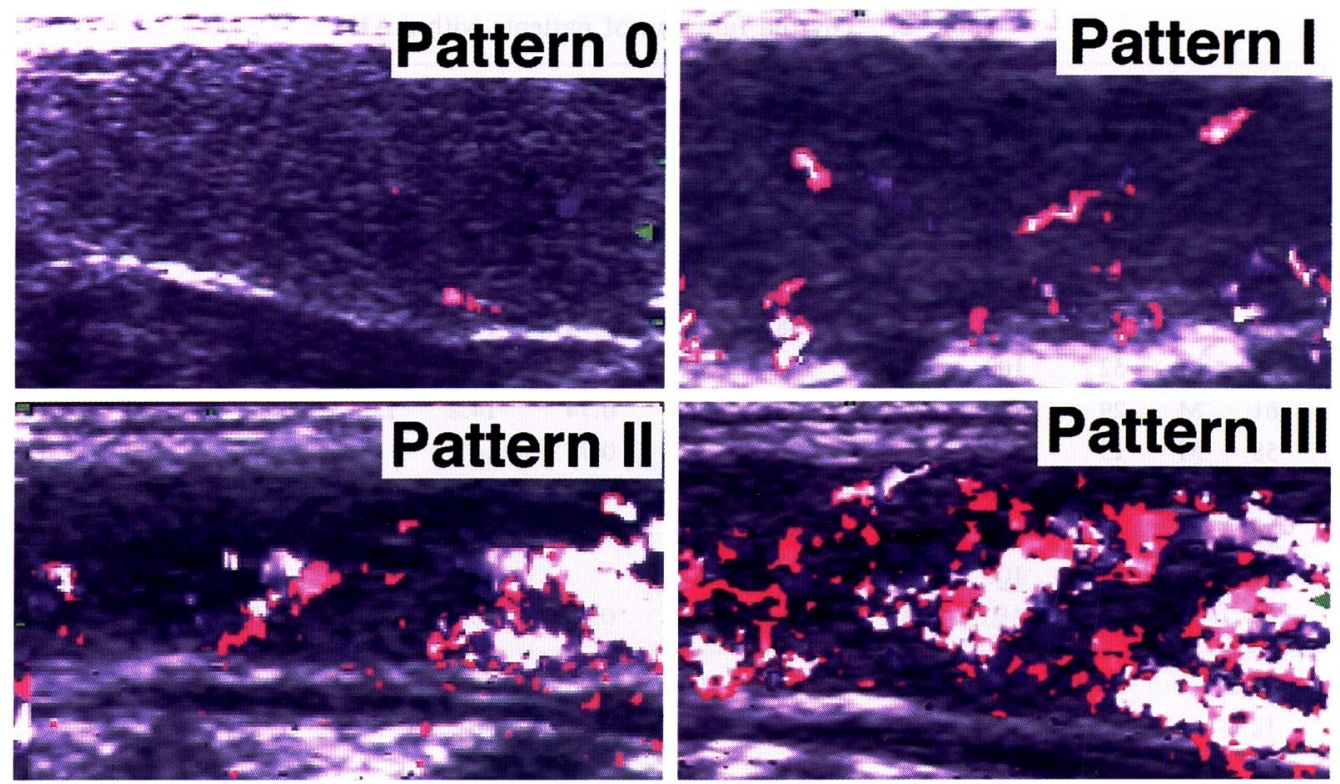

Fig. 1. Patterns of color flow Doppler sonography Four patterns are shown; pattern 0 (obtained from an AIT patient), Pattern I (obtained from a patient with mild Graves' disease), Pattern II (obtained from a patient with moderate Graves' disease) Pattern III (obtained from a patient with severe Graves' disease).

Table 1. Thyroid function of patients with AIT

\begin{tabular}{|c|c|c|c|c|c|c|c|c|c|c|c|c|c|c|}
\hline Diagnosis & Age & Sex & $\begin{array}{l}\text { Duration } \\
\text { (months) }\end{array}$ & $\begin{array}{l}\text { Dose } \\
(\mathrm{mg})\end{array}$ & $\begin{array}{c}\mathrm{T} 3 \\
\text { (ng/dl) }\end{array}$ & $\begin{array}{c}\text { fT3 } \\
(\mathrm{pg} / \mathrm{ml})\end{array}$ & $\begin{array}{c}\mathrm{T} 4 \\
(\mu \mathrm{g} / \mathrm{dl})\end{array}$ & $\begin{array}{c}\mathrm{fT} 4 \\
(\mathrm{ng} / \mathrm{dl})\end{array}$ & $\begin{array}{c}\text { TSH } \\
(\mu \mathrm{U} / \mathrm{ml})\end{array}$ & $\begin{array}{c}\text { TRAb } \\
(\%)\end{array}$ & $\begin{array}{c}\mathrm{Tg} \\
(\mathrm{ng} / \mathrm{ml})\end{array}$ & Anti-Tg & Anti-mc & Treatment \\
\hline 1 ARVD & 37 & M & 38 & $150^{*}$ & 600 & 22 & 25.9 & 7.54 & $<0.1$ & 14.1 & 2538 & $<100$ & $<100$ & MMI \\
\hline $2 \mathrm{OMI}$ & 61 & $\mathbf{M}$ & 31 & $150^{*}$ & 710 & 27.7 & 22.6 & 10.1 & $<0.1$ & 2.3 & 1660 & $<100$ & $<100$ & MMI (Dis) \\
\hline 3 ARVD & 43 & M & 24 & $150^{*}$ & 244 & 11.5 & 18.8 & 7.3 & $<0.1$ & 0.5 & 169 & $<100$ & $<100$ & MMI \\
\hline $4 \mathrm{DCM}$ & 27 & M & 24 & $150^{*}$ & 331 & 9.9 & 17.4 & 3.3 & $<0.1$ & 1.4 & 440 & $<100$ & $<100$ & $(-)$ \\
\hline $5 \mathrm{OMI}$ & 68 & $\mathrm{~F}$ & 37 & 100 & 193 & 5.7 & 14.6 & 2.95 & $<0.005$ & 6.9 & 59 & & & MMI \\
\hline 6 ARVD & 69 & $\mathbf{M}$ & 48 & 200 & 170 & 6.9 & 14.3 & 3.2 & $<0.1$ & 6.4 & 40 & & & $(-)$ \\
\hline $7 \mathrm{VT}$ & 61 & M & 37 & $150^{*}$ & 227 & 9.4 & 13.9 & 4.07 & $<0.1$ & 8.1 & 71 & $<100$ & 800 & $(-)$ \\
\hline $8 \mathrm{DCM}$ & 40 & M & 40 & $150^{*}$ & 200 & 5.7 & 13.1 & 2.98 & $<0.1$ & 2 & 135 & $<100$ & $<100$ & $(-)$ \\
\hline $9 \mathrm{DCM}$ & 54 & $\mathrm{~F}$ & 99 & 100 & 205 & & 12.5 & & $<0.005$ & 3 & & & & PDN \\
\hline $10 \mathrm{OMI}$ & 70 & $\mathbf{M}$ & 10 & $150^{*}$ & 111 & 3.5 & 11.9 & 2.35 & $<0.1$ & 0.3 & 5 & $<100$ & $<100$ & $(-)$ \\
\hline $11 \mathrm{DCM}$ & 51 & M & 37 & 200 & 140 & 4.8 & 11.4 & 2.63 & $<0.027$ & 1 & 24 & $<100$ & $<100$ & $(-)$ \\
\hline $12 \mathrm{OMI}$ & 73 & M & 33 & 200 & 118 & 6 & 11.4 & 2.63 & & 6.6 & 122 & & & $(-)$ (Dis) \\
\hline 13 OMI & 70 & $\mathbf{M}$ & 52 & 100 & 135 & 5.6 & 10.5 & 2.86 & $<0.005$ & 2.8 & 76.6 & $<100$ & $<100$ & \\
\hline Mean & 55.7 & & 39.2 & 150 & 260 & 9.9 & 15.3 & 4.3 & & 4.3 & 445 & & & \\
\hline $\mathrm{SD}$ & 15 & & 20.9 & 35 & 186 & 7.4 & 4.7 & 2.5 & & 4 & 803 & & & \\
\hline
\end{tabular}

Dose and duration of amiodarone adminstration; $150 \mathrm{mg}^{*}: 100$ and $200 \mathrm{mg}$ on alternate days, TRAb: TSH receptor antibody, $\mathrm{Tg}$ : thyroglobulin, Anti-Tg: anti-thyrogbolulin antibody titer, Anti-mc: anti-microsomal antibody titer, ARVD: arrhythmogenic right ventricular dysplasia, OMI: old myocardial infarction, DCM: dilated cardiomyopathy, VT: ventricular tachycardia, MMI: methimazole, PDN: prednisolone, Dis: amiodarone was discontinued 
Table 2. Thyroid function of patients with AAH

\begin{tabular}{|c|c|c|c|c|c|c|c|c|c|c|c|c|c|c|c|}
\hline & Diagnosis & Age & Sex & $\begin{array}{l}\text { Duration } \\
\text { (months) }\end{array}$ & $\begin{array}{l}\text { Dose } \\
\text { (mg) }\end{array}$ & $\begin{array}{c}\text { T3 } \\
\text { (ng/dl) }\end{array}$ & $\begin{array}{c}\mathrm{fT} 3 \\
(\mathrm{pg} / \mathrm{ml})\end{array}$ & $\begin{array}{c}\mathrm{T} 4 \\
(\mu \mathrm{g} / \mathrm{dl})\end{array}$ & $\begin{array}{c}\mathrm{fT} 4 \\
\text { (ng/dl) }\end{array}$ & $\begin{array}{c}\text { TSH } \\
(\mu \mathrm{U} / \mathrm{ml})\end{array}$ & $\begin{array}{c}\text { TRAb } \\
(\%)\end{array}$ & $\begin{array}{c}\mathrm{Tg} \\
(\mathrm{ng} / \mathrm{ml})\end{array}$ & Anti-Tg & Anti-mc & Treatment \\
\hline 1 & OMI & 61 & $\mathbf{M}$ & 13 & 100 & 121 & 2.73 & 4.6 & 0.47 & 100.4 & & 186 & & & $\mathrm{~T} 4$ \\
\hline 2 & ARVD & 62 & $\mathbf{M}$ & 5 & 200 & & 2.97 & & 0.51 & 78 & 6.9 & 212 & & & $\mathrm{~T} 4$ \\
\hline 3 & $\mathrm{DCM}+\mathrm{CRF}$ & 53 & $\mathbf{M}$ & 1 & 100 & 115 & & 6.7 & & 22.2 & 5.2 & 186 & & & $\mathrm{~T} 4$ \\
\hline 4 & DCM & 51 & $\mathrm{~F}$ & 35 & 100 & 143 & 2.88 & 5.1 & 0.74 & 17.9 & 2.8 & 487 & $<100$ & $<100$ & $\mathrm{~T} 4$ \\
\hline 5 & ARVD & 56 & $\mathbf{M}$ & 52 & 100 & 74 & & 5.3 & & 15.3 & 6.2 & 85 & $<100$ & $<100$ & $\mathrm{~T} 4$ \\
\hline 6 & HOCM & 61 & $\mathbf{M}$ & 29 & $150^{*}$ & 74 & 2.37 & 3.8 & 0.74 & 14.2 & 13.6 & 54 & $<100$ & $<100$ & $\mathrm{~T} 4$ \\
\hline 7 & OMI & 58 & $\mathbf{M}$ & 13 & 250 & & 2.26 & & 0.77 & 14 & & & $<100$ & $<100$ & $\mathrm{~T} 4$ \\
\hline 8 & OMI & 65 & $\mathbf{M}$ & 31 & 100 & 142 & 3.3 & 7.3 & 0.9 & 13.5 & 0.1 & 225 & $<100$ & $<100$ & $\mathrm{~T} 4$ \\
\hline 9 & VT & 28 & $\mathbf{M}$ & 9 & 100 & 106 & 2.5 & 6.2 & 1 & 13.2 & 5.4 & 190 & $<100$ & $<100$ & $\mathrm{~T} 4$ \\
\hline 10 & ARVD & 29 & $\mathbf{M}$ & 27 & 100 & 97 & & 7.2 & & 11 & 3.9 & & $<100$ & $<100$ & $\mathrm{~T} 4$ \\
\hline 11 & $\mathrm{DCM}$ & 54 & $\mathbf{M}$ & 8 & $150^{*}$ & 114 & 2.9 & 5.3 & 0.7 & 10.4 & 6.3 & 235 & $<100$ & $<100$ & $\mathrm{~T} 4$ \\
\hline & Mean & 52.6 & & 20.3 & 132 & 110 & 2.8 & 5.7 & 0.73 & 28.2 & 5.8 & 207 & & & \\
\hline & SD & 12.6 & & 15.3 & 51 & 25 & 0.34 & 1.2 & 0.18 & 30.7 & 3.9 & 122 & & & \\
\hline
\end{tabular}

The abbrebiations are as indicated in Table 1. CRF: chronic renal failure, HOCM: hypertrophic obstructive cardiomyopathy

$\mathrm{T}_{3}, \mathrm{~T}_{4}$, free $\mathrm{T}_{4}$ and thyroglobulin had all increased to $260 \pm 186 \mathrm{ng} / \mathrm{dl}, \quad 9.9 \pm 7.4 \mathrm{pg} / \mathrm{ml}, \quad 15.3 \pm 4.7$ $\mu \mathrm{g} / \mathrm{dl}, \quad 4.3 \pm 2.5 \mathrm{ng} / \mathrm{dl}$, and $445 \pm 803 \mathrm{ng} / \mathrm{ml}$, respectively, in the AIT patients, accompanied by suppressed levels of TSH $(<0.1 \mu \mathrm{U} / \mathrm{ml})$. In the AAH patients, serum levels of total $T_{3}$ and $T_{4}$ were at the lower end of the normal range or slightly decreased, accompanied by increased serum levels of TSH $(28.2 \pm 30.7 \mu \mathrm{U} / \mathrm{ml})$ and thyroglobulin $(207 \pm$ $122 \mathrm{ng} / \mathrm{ml})$.

One of 13 patients with AIT was positive for TRAb. Furthermore, one of the 11 patients with AAH developed TRAb transiently. Antimicrosomal antibody was positive in one of 9 AIT patients, whereas anti-thyroglobulin antibody was negative in all $\operatorname{AIT}(n=9)$ and AAH $(n=7)$ patients.

Consistent with a previous report [18], urinary excretion of iodide was also markedly increased in patients with AIT $(6.5 \pm 1.0 \mathrm{mg} / \mathrm{gCr}$, mean $\pm \mathrm{SD}$, $\mathrm{n}=6)$ and $\mathrm{AAH}(7.0 \pm 1.0 \mathrm{mg} / \mathrm{g} \mathrm{Cr}$, mean $\pm \mathrm{SD}$, $\mathrm{n}=4)$ than in normal subjects $(0.31 \pm 0.021 \mathrm{mg} / \mathrm{g}$ $\mathrm{Cr})$, but there was no significant difference between levels in AIT and AAH patients $(\mathrm{P}>0.1)$.

\section{Ultrasound sonography and color flow Doppler sonography}

The estimated thyroid volume was increased to $23.7 \pm 5.6 \mathrm{ml}$ in AIT (mean $\pm \mathrm{SD}, \mathrm{n}=10$ ) and
$21.2 \pm 1.8 \mathrm{ml}$ in $\mathrm{AAH}($ mean $\pm \mathrm{SD}, \mathrm{n}=6$ ), which was significantly smaller than in Graves' disease $(P<0.05)$. The internal texture of the thyroid in patients with AIT and AAH showed a decreased echogenecity with no nodular lesion. Consistent with a previous report [17], the pattern 0 was found in all patients with AIT $(n=7)$. In patients with AAH, however, color flow varied from pattern 0 to II, depending on serum TSH levels. In contrast, patterns II and III were observed in patients with untreated Graves disease $(n=10)$ (data not shown) [19].

\section{Clinical course and treatment of $A I H$ patients}

The thyroid glands of AIT patients were almost all of the normal size or only slightly enlarged, except for case 1 , in whom the thyroid gland was moderately enlarged. The thyroid gland was non-tender on palpation in all the AIT patients.

As shown in Table 1, four patients with marked thyrotoxicosis were treated with methimazole. Despite administration of this antithyroid drug, the increased serum levels of $T_{3}$ and $T_{4}$ persisted for a prolonged period. In one patient with arrhythmogenic right ventricular dysplasia (ARVD), who developed the severest AIT, accompanied by positive TRAb, serum levels of TSH were suppressed to less than $<0.1 \mu \mathrm{U} / \mathrm{ml}$ for 9 months [13]. This TRAb 


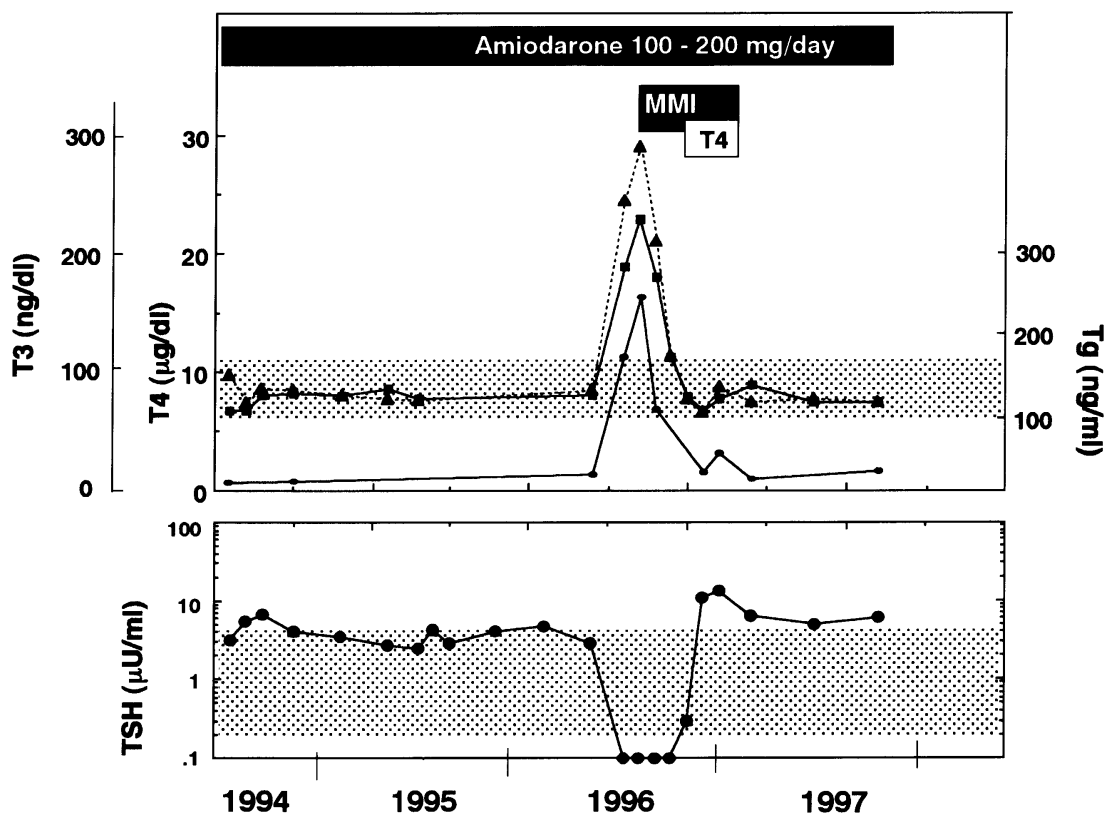

Fig. 2. Thyroid function of a patient with severe AIT, treated with methimazole. A 43-year-old-patient with arrhythmogenic right ventricular dysplasia (Table 1, case 3) developed moderate thyrotoxicosis 2 years after taking amiodarone. Methimazole (MMI) was prescribed, without discontinuing amiodarone. After three months, serum levels of $T_{3}$ and $\mathrm{T}_{4}$ normalized, but serum level of TSH remained slightly elevated, even after one and a half years. Dotted areas indicate normal ranges of total $\mathrm{T}_{4}$ (upper panel) and TSH (lower panel). Upper panel: $\boldsymbol{\Delta} \cdots \mathbf{\Delta} ; \mathrm{T}_{3}(\mathrm{ng} / \mathrm{dl}), \boldsymbol{\square}-\mathbf{\square} ; \mathrm{T}_{4}(\mu \mathrm{g} / \mathrm{dl})$, - $\mathrm{Tg}(\mathrm{ng} / \mathrm{ml})$, Lower panel: $\mathrm{TSH}(\mu \mathrm{U} / \mathrm{ml})$.

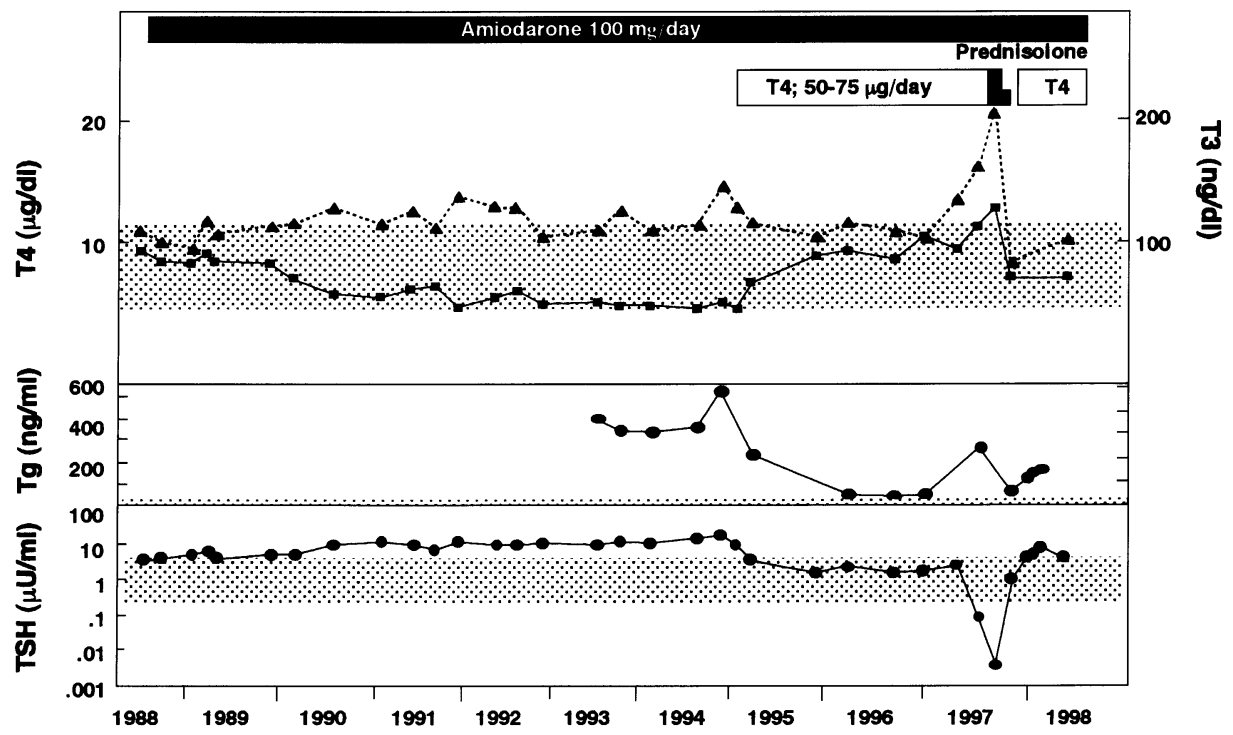

Fig. 3. Thyroid function of a patient with mild AIT, treated with prednisolone. A 54-year-old patient with dilatated cardiomyopathy (Table 1, case 9) gradually became hypothyroid. L-thyroxine $\left(\mathrm{T}_{4}\right)$ was prescribed until October 1997 , when mild AIT developed. Prednisolone was prescribed for two months, and the patient became euthyroid in a few months. The patient has been taking amiodarone continuously for the last 10 years. The dotted areas indicate normal ranges of total $\mathrm{T}_{4}$ (upper panel), thyroglobulin (mid-panel), and TSH (lower panel). Upper panel: $\boldsymbol{\Delta} \cdots \mathbf{\Delta} ; \mathrm{T}_{3}(\mathrm{ng} / \mathrm{dl}$ ), - $-\mathbf{a} ; \mathrm{T}_{4}(\mu \mathrm{g} / \mathrm{dl})$. 
did not elicit any thyroid hormone-releasing activity, suggesting that the antibody developed after destructive thyroiditis [13]. Another 43-year-old patient with ARVD was also treated with methimazole, without discontinuing amiodarone [20]. The thyrotoxicosis continued for more than 4 months,

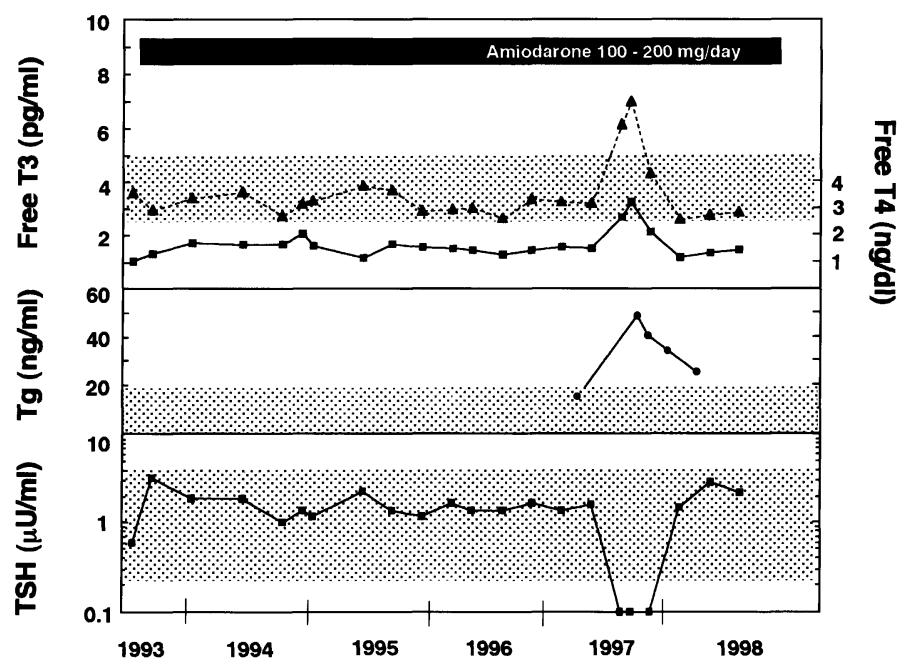

Fig. 4. Thyroid function of a patient with mild AIT, which resolved spontaneously. A 69-year-old patient with arrythmogenic right ventricular dysplasia (Table 1, case 6) developed mild AIT 4 years after starting amiodarone. The thyrotoxicosis resolved spontaneously without any treatment. The peak levels of total $\mathrm{T}_{4}$ and $\mathrm{fT}_{4}$ were $14.3 \mu \mathrm{g} / \mathrm{dl}$ and $6.9 \mathrm{pg} / \mathrm{ml}$, respectively. The patient has been taking amiodarone continuously for the last 5 and half years. Dotted areas indicate normal ranges of free $\mathrm{T}_{3}$ (upper panel), thyroglobulin (mid-panel) and TSH (lower panel). Upper panel: $\mathbf{\Delta} \cdots \mathbf{\Delta} ; \mathrm{fT}_{3}$ (ng/dl), $\square-\mathrm{fT}_{4}(\mathrm{ng} / \mathrm{dl})$.

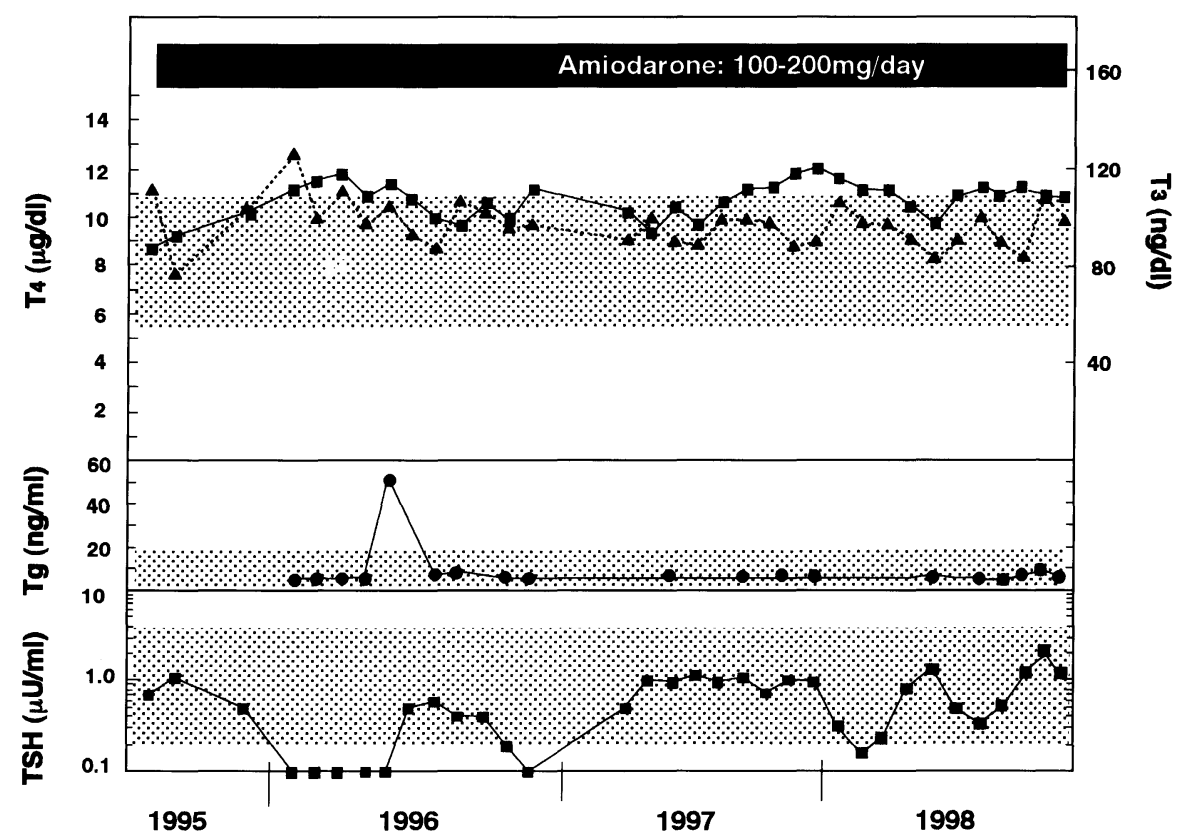

Fig. 5. Thyroid function of a patient with asymptomatic AIT. A 70-year-old patient with old myocardial infarction (Table 1, case 10) was taking amiodarone for the last 3 years. Serum TSH decreased repeatedly to below $0.1 \mu \mathrm{U} / \mathrm{ml}$, but the patient is doing well, without any hyperthyroid symptoms. Dotted areas indicate normal ranges of total $\mathrm{T}_{4}$ (upper panel), thyroglobulin (mid-panel), and TSH (lower panel). Upper panel: $\boldsymbol{\Delta} \cdots \boldsymbol{\Delta} ; \mathrm{T}_{3}(\mathrm{ng} / \mathrm{dl}), \mathbf{\square}-\mathbf{\square} ; \mathrm{T}_{4}(\mu \mathrm{g} / \mathrm{dl})$. 
accompanied with elevated serum levels of $T_{4}, T_{3}$, and Tg (Fig. 2). The serum level of TSH was suppressed to below $0.1 \mu \mathrm{U} / \mathrm{ml}$ for four months, and remained slightly high after 1 year, when all the medication was withdrawn. In the other two cases, the thyrotoxic period persisted for at least 3 months. After AIT completely resolved, serum level of TSH remained slightly high in three of four patients (4-8 $\mu \mathrm{U} / \mathrm{ml})$, suggesting that subclinical hypothyroidism persisted after a noticeable destructive process in the thyroid of these patients [21].

A female patient with sustained ventricular tachycardia due to dilated cardiomyopathy developed AAH after taking amiodarone for 4 years, and L-thyroxine was prescribed at a daily dose of 50-75 $\mu \mathrm{g}$ until April 1997, when mild AIT developed. Prednisolone was prescribed, without discontinuing the antiarrhythmic, and the thyrotoxicosis resolved in a few months (Fig. 3).

Eight patients developed mild (total $\mathrm{T}_{4} ; 10-12$ $\mu \mathrm{g} / \mathrm{dl}$ ) to moderate thyrotoxicosis (total $\mathrm{T}_{4} ; 12.5-17.4$ $\mu \mathrm{g} / \mathrm{dl}$ ), which subsided spontaneously in a few months without any treatment (Fig. 4). In the four mild AIT patients with asymptomatic thyrotoxicosis, serum levels of $T_{4}, \mathrm{fT}_{4}, \mathrm{~T}_{3}$, and $\mathrm{fT}_{3}$ were in the upper normal range or slightly high, and the serum level of TSH was suppressed to below $0.1 \mu \mathrm{U} / \mathrm{ml}$, accompanied with increased thyroglobulin, suggesting a destructive type of thyrotoxicosis. In one patient, such a subclinical thyrotoxicosis had occurred twice in the last 4 years without any subjective symptoms (Fig. 5).

Eleven AIT patients continued amiodarone despite the drug-induced thyrotoxicosis without any additional adverse effects (Fig. 2-5), but two patients had to discontinue amiodarone, because of deterioration of pulmonary function $(n=1)$ and multiple organ failure $(n=1)$.

\section{Clinical course and treatment of $A A H$ patients}

When AAH developed, the patients were simply supplemented with L-thyroxine. At a daily dose of $50-100 \mu \mathrm{g}$ L-thyroxine, all of them remained euthyroid without discontinuing amiodarone.

\section{Discussion}

Although it is reported that AIT is less frequent in areas where iodine intake is sufficient [11], we have observed 13 patients with AIT in the last 6 years. Recently it was postulated by Italian physicians that there are two types of AIT: namely, type I AIT, which develops in an abnormal thyroid gland with excessive synthesis of thyroid hormone, and is characterized by maintained or elevated ${ }^{123}$ I uptake, ultrasound abnormalities (hypoechoic pattern and nodular lesions), and a normal to slightly high IL-6 level [22]. In contrast, type II AIT develops in an apparently normal thyroid, showing suppressed ${ }^{123}$ I uptake, a normal ultrasound pattern, and a markedly increased IL-6 concentration, simulating destructive thyroiditis. There is as yet no general consensus on the treatment of AIT, but antithyroid agents are recommended for the treatment for type I, and glucocorticoids for type II AIT [1, 22]. From an endocrinological point of view, it is very important to quickly make a differential diagnosis of type I and type II AIT. Among several tests, ${ }^{123}$ I uptake is the most reliable in making a differential diagnosis of types I and II [7], but it is not our practice to ask the patients to visit the hospital again only for differential diagnosis. Furthermore, serum levels of IL- 6 may be overlapped in a few patients [18] and it takes a couple of weeks until the results arrive.

Increased serum levels of $T_{3}, T_{4}$ and thyroglobulin, with suppressed serum levels of TSH, and negative thyroid hormone-releasing activity in the serum in the AIT patients [13] suggest that the thyrotoxicosis is not due to a stimulation-induced but due to a destruction-induced process. In an asymptomatic AIT patient, we observed that the serum level of TSH decreased to less than $0.1 \mu \mathrm{U} / \mathrm{ml}$ repeatedly in the last 4 years, suggesting that minimal destructive thyroiditis was exacerbated and subsided repeatedly. Very recently Pitsiavas et al. [23] demonstrated that amiodarone induces direct cytotoxic effects on rat thyrocytes in vivo, such as necrosis, apoptosis, marked lipofucsinogenesis and markedly dilated endoplasmic reticulum, reminiscent of endoplasmic reticulum storage disease. Presumably a clinically silent thyroiditis may lower the intrathyroidal amiodarone concentration, allowing the repair phase to proceed uninterrupted [24]. Whether such decreased serum levels of TSH or a suppressed response of TSH to TRH test [25] may predict the development of clinically overt AIT remains to be elucidated in a prospective study in a greater number of patients. 
Very recently Bogazzi et al. [17] reported that differential diagnosis between type I and II AIT can be made rapidly by color flow Doppler sonography, by demonstration of hypervascularity in type I and absent or decreased vascularity in type II. In contrast to their observation that there were type I and type II AIT in 11 and 16 patients, respectively, we could not demonstrate any hypervascular lesion in our 13 AIT patients, suggesting that all the AIT patients we have seen so far had developed type II AIT. Such a greatly different incidence of AIT subtypes in Italy and Japan may be due to the different amount of iodine intake. If a patient has latent Graves disease in our country, he or she will easily manifest hyperthyroidism before any iodine-containing agent is prescribed. Furthermore, there are only a few patients with multinodular goiter which becomes autonomously thyrotoxic in our country [26]. In any event, iodine-induced hyperthyroidism is rarely seen in Japan $[27,28]$.

As expected, urinary excretion of iodide was greatly increased in both AIT and AAH patients. We could not demonstrate any significant difference between them. Nevertheless, if urinary iodide excretion is longitudinally measured in AIT patients, it may be increased in the thyrotoxic period, as demonstrated in the thyrotoxic phase of patients with painless thyroiditis [29].

As far as treatment for AIT is concerned, we have gained the impression that the antithyroid drug, methimazole, was not effective in ameliorating the thyrotoxicosis. In contrast, glucocorticoid seemed to rapidly ameliorate the thyrotoxicosis in one patient with moderate AIT, but in 8 patients with mild to moderate AIT, the thyrotoxicosis spontaneously resolved in a few months without any treatment. We are of the same opinion as other clinicians concerning the administration of glucocorticoid to symptomatic AIT patients, if thyrotoxicosis is severe $[1,7,22]$. Whether other methods such as lithium and perchlorate are effective, remains to be evaluated in future studies $[1,7,30]$.

In summary, since the introduction of amiodarone onto the market in 1992, AIT has been increasing in our country where iodine intake is still sufficient. When a patient taking amiodarone became thyrotoxic, ultrasonographic study and particularly color flow Doppler sonography is recommended for differential diagnosis of types I and II AIT. So far, all the AIT patients we have seen developed destruction-induced thyrotoxicosis (type II), which is unpredictable with an unexplained sudden onset. The rare incidence of type I AIT would be accounted for by a sufficient intake of iodine and a rare incidence of toxic multinodular goiter in our country. Amiodarone is not necessarily to be discontinued in patients with AIT as well as AAH, but the agent was discontinued in 2 of 23 patients in whom a severe extrathyroidal adverse reaction developed.

\section{Acknowledgments}

This work was partly supported by a Grant-in-Aid for Scientific Research from the Ministry of Education, Science and Culture of Japan (07671158).

\section{References}

1. Harjai KJ, Licata AA (1997) Effects of amiodarone on thyroid function. Ann Intern Med 126: 63-73.

2. Gill J, Heel RC, Filton A (1992) Amiodarone. An overview of its pharmacological properties, and review of its therapeutic use in cardiac arrhythmia. Drugs 43: 69-110.

3. Beddows SA, Page S, Taylor AH, McNerney R, Whitely GS, Johnstone AP, Nussey SS (1989) Cytotoxic effects of amiodarone and desethylamiodarone on human thyrocytes. Biochemical Pharmacology 38: 4397-4403.

4. Chiovato L, Martino E, Tonacchera M, Santini F, Lapi P, Mammoli C, Braverman LE, Pinchera A (1994) Studies on the in vitro cytotoxic effect of amiodarone. Endocrinology 134: 2277-2282.

5. Trip MD, Wiersinga W (1991) Incidence, predictability, and pathogenesis of amiodarone-induced thyrotoxicosis and hypothyroidism. Am J Med 91: 507-511.11.

6. Wilson JS, Podrid PJ (1991) Side effects from amiodarone. Am Heart J 121: 158-171.

7. Newman CM, Price A, Davies DW, Gray TA, Weetman AP (1998) Amiodarone and the thyroid: a practical guide to the management of thyroid dysfunction induced by amiodarone therapy. Heart 79: 121-127.

8. Peche R, Abramowicz M, Unger J (1992) Failure to respond to dexamethasone with fatal consequences, 
after initial response to multidrug treatment in a case of amiodarone-associated thyrotoxicosis. $\mathrm{Am} \mathrm{J} \mathrm{Med}$ 93: 702-703.

9. Georges JL, Normand JP, Lenormand ME, Schwob J (1992) Life-threatening thyrotoxicosis induced by amiodarone in patients with benign heart disease. Europ Heart J 13: 129-132.

10. Samaras K, Marel GM (1996) Failure of plasmapheresis, corticosteroids and thionamides to ameliorate a case of protracted amiodarone-induced thyroiditis. Clin Endocrinol 45: 365-368.

11. Martino, E., Safran, M., Aghini-Lombardi, F. Rajatanavin R, 0 Lenziardi M, Fay M, Pacchiarotti A, Aronin N, Mcchia E, Haffajee C, Odoguardi L, Love J, Bigalli A, Bashieri L, Pinchera A, Braverman L (1984) Environmental iodine intake and thyroid dysfunction during chronic amiodarone therapy. Ann Inter Med 101: 28-34.

12. Hayashi K, Sone T, Suzuki T, Numaguchi Y, Kondoh J, Tsuboi H, Sassa H (1997) A case of amiodaroneinduced thyrotoxicosis successfully treated with prednisolone. Jpn Circ J 61: 361-366.

13. Sato K, Yamazaki K, Kanaji Y, Ohnishi S, Kasanuki H. (1998) Amiodarone-induced thyrotoxicosis associated with TSH receptor antibody. Thyroid 8: 1123-1126.

14. Ishizuki Y, Hirooka Y, Tanigawa S (1994) The variation of Japanese urinary excretion of iodine in different decades of age. Folia Endocrinol 70: 10931100 (in Japanese, with English abstract).

15. Zak B, Willard HH, Myers GB, Boyle A.J (1952) Cholic acid method for determination of proteinbound iodine. Analytical Biochemistry 24: 13451348.

16. Vitti P, Rago T, Mazzeo S, Brogioni S, Lampis M, De Liperi A, Bartolozzi C, Pinchera A, Martino E (1995) Thyroid blood flow by color-flow doppler sonography distinguishes Graves' disease from Hashimoto's thyroiditis. J Endocrinol Invest 18: 857-861.

17. Bogazzi F, Bartalena L, Brogioni S, Mazzeo S, Vitti P, Burelli A, Bartolozzi C, Martino E (1997) Color flow doppler sonography rapidly differentiates type I and type II amiodarone-induced thyrotoxicosis. Thyroid 7: 541-545.

18. Rao RH, McCready VR, Spathis GS (1986) Iodine studied during amiodarone treatment. $J$ Clin Endocrinol Metab 62: 563-568.

19. Iitaka M, Miura S, Yamanaka K, Kawasaki S, Katahama S, Kawakami Y, Kakinuma S, Oosuga I, Wada S, Katayama S (1998) Increased serum vascular endothelilal growth factor levels and intrathyroidal vascular area in patients with Graves disease and Hashimoto's thyroiditis. J Clin Endocrinol Metab 83: 3908-3912.

20. Trip MD, Duren DR, Wiersinga WM (1994) Two cases of amiodarone-induced thyrotoxicosis successfully treated with a short course of antithyroid drugs while amiodarone was continued. $B r$ Heart $J$ 72: 266-268.

21. Rotti E, Minellli R, Gardini E, Bianconi L, Braverman LE (1993) Thyrotoxicosis followed by hypothyrodism in patients treated with amiodarone: a possible consequence of a destructive process in the thyroid. Arch Intern Med 153: 886-892.

22. Bartalena L, Brogioni S, Grasso L, Nogazzi F, Burelli A, Martino E (1996) Treatment of amiodaroneinduced thyrotoxicosis, a difficult challenge: results of a prospective study. J Clin Endocrinol Metab 81: 2930-2933.

23. Pitsiavas V, Smerdely P, Li M, Boyages S (1997) Amiodarone induces a different pattern of ultrastructural change in the thyroid to iodine excess alone in both the $\mathrm{BB} / \mathrm{W}$ rat and the Wistar rat. Europ $J$ Endocrinol 137: 89-98.

24. Wiersinga WM (1997) Towards an animal model of amiodarone-induced thyroid dysfunction. Europ $J$ Endocrinol 137: 15-17.

25. Staubli M, Struder H (1985) Amiodarone-treated patients with suppressed TSH test are at risk of thyrotoxicosis. Klin Wochenshr 63: 168-175.

26. Fujimoto Y. Thyroid nodules. In: Practical Approach to Clinical Endocrinology, edited by Fujimoto Y, p. 43-130, Chugai Igaku-sha, Tokyo, Japan, 1989 (in Japanese).

27. Fradkin JE, Wolff J (1983) Iodide-induced thyrotoxicosis. Medicine 62: 1-20.

28. Stanbury JB, Ermans AE, Bourdoux P, Todd C., Oken E, Tonglet R, Vidor G, Braverman LE, Medeiros-Neto G (1977) Iodine-induced hyperthyroidism: occurrence and epidemiology. Thyroid 8: 83-100.

29. Sugimoto $T$, Momotani N, lino S, Ito $\mathrm{K}$ (1994) Clinical significance of the measurement of the urinary concentration of iodine: differentiating silent thyroiditis from Graves disease. Folia Endocrinol 70: 1083-1092 (In Japanese).

30. Dickstein G, Shrechner C, Adawi F, Kaplan J, Baron E, Ish-Shalom S (1997) Lithium treatment in amiodarone-induced thyrotoxicosis. Am J Med 102: 454458 . 